\title{
REFLEXÃO SOBRE A PRATICA DO ENSINO DA ENFERMAGEM PSIQUIÁTRICA E SAÚDE MENTAL
}

\author{
* Josicélia Dumêt Fernandes
}

RBEn/06

FERNANDES, J.D. - Reflexão sobre a prática do ensino da enfermagem psiquiátrica e saúde mental. Rev. Bras. Enf.; DF, 403-406, 1979.

\section{I - INTRODUÇAOO}

Entendendo-se "prática" como um processo de trabalho e como tal, um processo de transformação, um processo de relaçōes sociais, a reflexão sobre a prática profissional surge como uma imposição numa época em que se tornam necessárias não apenas as mudanças nas direçōes da enfermagem, mas também estudos críticos dos seus princípios básicos, do seu valor, do seu alcance e de suas relaçōes com a sociedade. Essa imposição constitui o resultado de uma lacuna nas práticas anteriores, e até mesmo atuais, que deverão ser conscientizadas e ultrapassadas pela adição de novos princípios e métodos.

Nas últimas décadas tem havido uma grande preocupação nesse sentido, Lsto é, no que diz respeito às mudanças e inovaçōes dos padrōes tradicionais na formação do enfermeiro. Todavia na área do ensino da enfermagem psiquiátrica e saúde mental, essas modificaçōes têm sido de natureza acessória, pois suas estruturas têm permanecido quase que inalteradas. Apesar de alguns esforços, isolados ou grupais, visando a busca ae soluçōes dos problemas existentes, o ensino da enfermagem psiquiátrica e saúde mental continua evidenciando uma profunda separação com as reais necessidades de saúde da população, mantendo uma visão parcial da realidade social em que está implantado.

Essa situação é, em última análise determinada pelos condicionantes sociais em que a Escola é um reflexo dos mesmos. As açōes e modificaçōes na prática do ensino da enfermagem (e da enfermagem psiquiátrica e saúde mental) atendem às exigências do dinamismo social, articulando-se com os determinantes estruturais da sociedade, dai o fato de ser considerada como uma prática so cial historicamente determinada.

* Professor Adjunto da Escola de Enfermagem da Universidade Federal da Bahia. Professora de Enfermagem Psiquítrica da Escola de Fnfermagem da Univeraldade Federal da Bahia. 
FERNANDES, JD. - Reflexão sobre a prática do ensino da enfermagem psiquiátrica e saúde mental. Rev. Bras. Enf.; DF, 403-406, 1979.

Este trabalho é fruto de uma análise critica induzida por uma realidade desafiadora, abrindo terreno fértil para a reflexão da prática profissional nos dias atuais e tem como objetivos:

- Abordar alguns aspectos referentes à estrutura do ensino da enfermagem psiquiátrica e saúde mental que poderiam favorecer a compreensão das práticas que nela se desenvolvem.

- Levantar alguns dos fatores que condicionam ou determinam a prática do ensino da enfermagem psiquiátrica e saúde mental.

Embora o objeto deste estudo constitua-se efetivamente sobre a prática do ensino da enfermagem psiquiátrica e saúde mental, ele não tem a pretensão de uma análise global da mesma, deixandose, desta forma, de proceder não só uma aborcagem intensiva dessa prática, mas também a elaboração de qualquer perspectiva imediata de interferência nesta área com vistas a reformulaçōes internas.

Espera-se, de alguma forma, servir de estímulo para que todos aqueles que exercem o ensino da enfermagem passem a se questionar sobre a objetividade e validade de sua própria prática, bem como oferecer subsidios para auxiliar os docentes a dar o salto qualitativo de uma consciência ingênua para uma consciência critica e a propor soluçōes mais reais para os problemas do ensino da enfermagem tendo em vista a saúde mental da população.

\section{II - ESTRUTURA DO ENSINO DA ENFERMAGEM PSIQUIATRICA E SAむDE MENTAL}

Nas últimas décadas tem havido um crescente interesse em todo o pais no sentido de despertar as escolas para a realidade que a cerca, mas, em última análise, todas as modificaçōes feitas no interior do ensino da enfermagem psiquiátrica e saúde mental prendem-se aos aspectos formais, havendo uma absorção de novas técnicas e novas terminologias, mantendo, entretanto, as características da estrutura antiga. Modifica-se programas, objetivos e cargas horárias da cisciplina, todavia o conteúdo continua revestido de características da antiga estrutura.

Contudo, essas consideraçōes não devem levar ao idealismo de acreditar-se que se pode explicar a totalidade da prática do ensino da enfermagem psiquiátrica e saúde mental pela análise do comportamento individual dos docentes nem das açōes das escolas. necessário identificar-se os fatores que, independentemente dos indivíduos, determinam a estrutura da prática do ensino. $\mathrm{E}$ essa prática comporta uma variedade de análises.

O desenvolvimento do ensino da enfermagem psiquiátrica e saúde mental como campo do saber é marcado por sucessivas transformaçōes - conseqüentes aos avanços da psiquiatria. Entretanto, a concepção desse desenvolvimento histórico como processo cumulativo de conhecimentos leva a acreditar-se que apesar da explosão dos psicofármacos, da ilusāo da Comunidade Terapêutica, do discurso moderno e bem intencionado da Psiquiatria Social e Psiquiatria Comunitária e prática psiquiátrica continua com características tradicionais, isto é, reproduzindo a exclusão/segregação do doente mental através dos hospitais psiquiátricos e dos ambulatórios restritos ao consumo medicamentoso, estabelecendose desta forma, a contradição entre as necessidades do indivíduo e a organização social das instituiçōes de assistência.

Por outro lado, devido ao alto custo da mão-de-obra especializada (o enfermeiro), a maior parte da população de enfermagem, nos hospitais psiquiátricos, é constituída por elementos praticamente leigos em Saúde Mental, havendo desta forma, na maioria dessas instituiçōes, um número reduzido de profissionais qualificados em relaçāo ao número de pacientes. Isso impossibilita o exercício da enfermagem psiquiátrica, dificultando o treinamento específico de pessoal e até 
FERNANDES, J.D. - Reflexảo sobre a prática do ensino da enfermagem psiquiátrica e saúde mental. Rev. Bras. Enf.; DF, 403-406, 1979.

mesmo a supervisão da assistência prestada.

Em outras palavras, a assistência psiquiátrica tem sido de má qualidade, precária e insuficiente para a grande maioria da população, como também tem sido caracterizada, com ênfase no modelo hospitalar, por uma prática repressiva, cronificadora e estigmatizante que pode ser traduzida por uma técnica anti-terapêutica que não atende às necessidades do doente (9).

Toda essa situação conduz a psiquiatria para ações cada. vez mais distantes do sofrer psíquico e mais forternente engaja com a estratégia de dominação, tanto nos aspectos político-ideológicos como nos econômicos, daí a sua relação com a sociedade.

As escolas por sua vez, utilizam as instituições psiquiátricas para estágio dos estudantes e, conseqiientemente, o ensino gira em torno do tipo de assistência prestada à população.

Por outro laōo, se as escolas preparam pessoal para atender ao mercado de trabalho, elas tentam responder às questōes que se encontram distantes das reais necessidades de saúde da população, para situar-se na busca de sua eficiência como instituição, com finalidade na dinâmica social, respondendo às demandas político-iáeológicas e econômicas, isto é, um ensino orientado na exclusão/segregação, na manutenção das normas e ritmos de produção, bem como no controle social e na manutenção da ordem pública. Observa-se um ensino preso aos aspectos formais, distanciado da realidade concreta das relações homem-mundo circundante, atuando apenas na aparência do fenômeno saúde-doença, esquecendo que este decorre das atividades sociais do homem.

Essas considerações evidenciam as contradições impostas ao ensino da enfermagem psiquiátrica e saúde mental. Todavia, mesmo que as escolas passassem a preparar um tipo de enfermeiro adequado às reais necessidades da popula- ção, provavelmente iria deparar-se com as características vigentes do atendimento em saúde mental. Fica então expressa a contradição: O enfermeiro deve ser preparado para atuar nas condiçōes do atual sistema de saúde mental ou para atuar num sistema modificado para atender as reais necessidades da maioria da população?

Com a finalidade de tentar amenizar essas contradiçōes, muitas discussōes têm sido realizadas e têm concluído na imperiosa necessidade de modificar-se os currículos, dando ênfase aos aspectos preventivos e sociais. Todavia, na maioria das vezes, essas reuniōes terminam $\mathrm{em}$ declarações de enunciados que não chegam a ser assumidos em todas as suas conseqüências, nem tampouco chegam a constituir-se numa formulação clara de procedimentos reais e objetivos que venham a permitir a incorporação efetiva desses conhecimentos no ensino da enfermagem psiquiátrica e saúde mental. Algumas das causas dessa situação fundamenta-se não só na relação do ensino com a estrutura social, mas também no fato de que as instituições escolares não respondem automaticamente ao projeto definido pela política educacional, isto é, os professores, na sua grande maioria, não cedem, na prática, em benefício do ensino dos aspectos preventivos e socials, senão em espaços de tempo muito llmitados.

O ensino da enfermagem psiquiátrica e saúde mental continua, pois, com uma abstração do conjunto global do fenômeno saúde-doença, persistindo, o seu conteúdo, voltudo para a assistência hospitalar. Assim está mantido o ensino dessa disciplina e a introdução constante de novas terminolugias bem com os planos de renovação até agora apresentados, não têm conseguido disfarçar a manutenção dos mesmos e velhos critérios de ensino e aprendizagem.

A compreensão das causas que explicam essas características, leva à necessidade da realização de análises hitórico- 
FERNANDES, J.D. - Reflexão sobre a prática do ensino da enfermagem psiquiátrica e saúde mental. Rev. Bras. Enf.; DF, 403-406, 1979.

estruturais para buscar na evolução do contexto social a explicação para a situação do ensino e das práticas de enfermagem, bem como para identificar, com mais propriedade, soluções e formas de ação.

Apesar de não se pretender, neste trabalho, uma abordagem histórica do ensino da enfermagem psiquiátrica e saúde mental, pode-se concluir que não se consegue explicar a prática do ensino apenas pelos fatores internos que nela atuam. Muitos dos fatores que ocorrem fora dessa prática, e que independem dela, sāo talvez mais importantes e determinantes do que mesmo os fatores internos. Um exemplo disso é o fato de que as escolas constituindo as instituiçōes responsávels pela prática do ensino, tendem a reproduzir as relaçōes sociais que predominam na sociedade em que está inserida, isto é, a relação entre a estrutura global da sociedade e o ensino da enfermagem psiquiátrica e saúde mental constitui o elemento determinante da mesma.

Assim náo se pode assumir raciocinios mecânicos, segundo os quais as escolas é que determinam o tipo de prática. Os problemas de ordem qualitativa e quantitativa são, portanto, originalmente, efeitos e não causas.

portanto, sobre a reflexão de toda essa situação da prática do ensino, que as soluções devem ser buscadas, com determinação e objetividade, bem como sem nenhuma carga de afetividade e com uma atitude modesta e aberta face à complexidade desconcertante da nossa realidade.

\section{III - BIBLIOGRAFIA}

01. CANDAU, V.M.F. - Perspectivas de Atualização Pedagógica no Ensino Superior. Rev. Clênclas Humanas, 2(7):35-39, out./dez 1978.

02. CASTF, $R$ - A Ordem Psiquiátrica. A Idade de Ouro do Alienismo. Rio de Janeiro, Graal, 1978.

03. CUNRA, LAA - Educação e Desenvolvimento Social no Brasil. Rio de Janeiro, Ed. Francisco Alves, 1977.

04. FRHTAG, B. - Escola, Estado e Sociedade. Såo Paulo, Cortez \& Moraes, 1979.

05. GARCIA, J.C. - La Educacion Medica en la America Latina. Washington, D.C., Publicacion Cientifica de la Organización Panamericana de la Salud, 1972.

06. MACEDO, C.G. - Recursos Humanos para a Saúde. Trabalho apresentado no XIX Congresso Brasileiro de Higiene e I Congresso Paulista de Saúde Pública. Sáo Paulo, out. 1977. Mimeografado.

07. NUNES FILHO, E.P. - Ensino em Saúde Mental. Rev. Ciênclas Humanas, 1(3):27-29, out./dez 1977.

08. PAIM, L. et alli - Inovaçōes no Ensino Superior de Enfermagem. Ansis do $\mathbf{X X X}$ Congresso Braslsileiro de Enfermagem, $A B E n-$ Belém, 1978.

09. PINHIIRO, L.H.F. - Assistência Psiquiátrica. Trabalho apresentado na I Jornada Psiquiátrica do Norte-Nordeste Brasileiro, abril, 1979, mimeografado.

10. SATNNAS, C.Q. - Enseñanzs de los Aspectos Integrales de la Salud o Aspectos Medico-Socinles: Eistoria $\boldsymbol{y}$ Situacion Atual. Edve. Med. Balod, 12(1):36-45, 1978.

11. WARDE, M.J. - Educação e Estrutura Boctal. Båo Paulo, Cortes \& Mo raes, 1979. 